\title{
Energy compensation following consumption of sugar-reduced products: a randomized controlled trial
}

\author{
Oonagh Markey $^{1,2} \cdot$ Julia Le Jeune $^{1} \cdot$ Julie A. Lovegrove $^{1,2}$
}

Received: 15 January 2015 / Accepted: 26 August 2015 / Published online: 9 September 2015

(C) The Author(s) 2015. This article is published with open access at Springerlink.com

\begin{abstract}
Purpose Consumption of sugar-reformulated products (commercially available foods and beverages that have been reduced in sugar content through reformulation) is a potential strategy for lowering sugar intake at a population level. The impact of sugar-reformulated products on body weight, energy balance (EB) dynamics and cardiovascular disease risk indicators has yet to be established. The REFORMulated foods (REFORM) study examined the impact of an 8-week sugar-reformulated product exchange on body weight, EB dynamics, blood pressure, arterial stiffness, glycemia and lipemia.

Methods A randomized, controlled, double-blind, crossover dietary intervention study was performed with fifty healthy normal to overweight men and women (age $32.0 \pm 9.8$ year, BMI $23.5 \pm 3.0 \mathrm{~kg} / \mathrm{m}^{2}$ ) who were randomly assigned to consume either regular sugar or sugarreduced foods and beverages for 8 weeks, separated by 4-week washout period. Body weight, energy intake (EI), energy expenditure and vascular markers were assessed at baseline and after both interventions.
\end{abstract}

Electronic supplementary material The online version of this article (doi:10.1007/s00394-015-1028-5) contains supplementary material, which is available to authorized users.

Julie A. Lovegrove

j.a.lovegrove@ reading.ac.uk

1 Hugh Sinclair Unit of Human Nutrition, Department of Food and Nutritional Sciences, University of Reading, Reading, Berkshire RG6 6AP, UK

2 Institute for Cardiovascular and Metabolic Research (ICMR), Department of Food and Nutritional Sciences, University of Reading, Reading, Berkshire RG6 6AP, UK
Results We found that carbohydrate $(P<0.001)$, total sugars $(P<0.001)$ and non-milk extrinsic sugars $(P<0.001)(\%$ EI $)$ were lower, whereas fat $(P=0.001)$ and protein $(P=0.038)$ intakes $(\% \mathrm{EI})$ were higher on the sugar-reduced than the regular diet. No effects on body weight, blood pressure, arterial stiffness, fasting glycemia or lipemia were observed.

Conclusions Consumption of sugar-reduced products, as part of a blinded dietary exchange for an 8-week period, resulted in a significant reduction in sugar intake. Body weight did not change significantly, which we propose was due to energy compensation.

Keywords Sugar · Sugar-reduced products · Obesity · Body weight $\cdot$ Dietary energy compensation $\cdot$ Artificial sweeteners

\section{Introduction}

There is much scientific debate regarding the potential impact of sugar consumption, especially in the form of sugar-sweetened beverages (SSB) ${ }^{5}$, on body weight status and various cardiometabolic health outcomes [1-5]. Specific policies on reducing over-consumption of energy and prevention of obesity and its comorbidities often include a recommendation to reduce sugar intake, as a means of reducing overall calorie intake and assisting with weight maintenance or prevention of weight gain $[6,7]$. WHO guidelines recommend a population daily target for free sugars, namely 'monosaccharides and disaccharides added to foods and beverages by the manufacturer, cook or consumer and the sugars naturally present in honey, syrups, fruit juices and fruit juice concentrates,' of $<10 \%$ of total energy intake (\% EI) [6]. A 
'conditional' recommendation for a limit of $<5 \%$ EI for free sugars was also suggested, as although the desirable effects of adherence to limiting free sugar intake to this value outweigh the undesirable effects to public health. Policy makers will require substantial debate with involvement of various stakeholders before translation to an unconditional recommendation [6].

Until recently, it was advised that the UK population average intake of 'non-milk extrinsic sugars' (NMES) should provide no more than $10 \%$ EI [8]. Data from the UK National Diet and Nutrition Survey (NDNS) highlight that population targets are currently being exceeded, with the mean NMES intakes of 11.5 and $14.9 \%$ EI in adults aged 19-64 year and children aged 4-18 year, respectively [9]. In 2015, the Scientific Advisory Committee on Nutrition (SACN) recommended that the definition for "free sugars' be adopted in the UK and advised that the population average intake of these sugars should not exceed $5 \%$ EI [10]. The only minor difference between free sugars and NMES is that the latter definition includes half of the quantity of the sugars in stewed, dried or preserved fruit [11].

Consumption of commercially available sugar-reduced foods and beverages is seen as a potential strategy to lower sugar intake, and potentially EI [12]. Recently, the WHO have suggested that their 2015 guidelines on sugar intake should be used to develop a strategy for reformulation of processed foods, such as those rich in free sugars [6]. However, it should be recognized that the replacement of sugar-sweetened products with sugar-reduced or artificially sweetened alternatives may be associated with compensatory responses in EI and/or energy expenditure (EE), which in turn may only lead to modest weight loss [13-15]. Yet there are very limited data on the efficacy of using sugar-reformulated products on body weight, energy balance (EB) dynamics and the possibility of energy compensation [16].

The impact of sugar consumption on physiological markers of health is not fully established, but emerging evidence suggests that sugar consumption may be linked to lipid dysregulation, hypertension and inflammation [17, 18]. In short-term human intervention studies, sucrose supplementation has been shown to significantly increase total and low-density lipoprotein (LDL) cholesterol [19], as well as systolic and diastolic blood pressure (BP) [20] in overweight participants. However, more research is needed to examine the link between sugar consumption and novel and traditional markers of cardiometabolic health using a more physiologically relevant dietary model of sugar intake.

The reformulated foods (REFORM) study tested the hypothesis that, if energy compensation does not occur, reducing NMES intake to $\leq 10 \%$ EI by exchanging reformulated, sugar-reduced foods and beverages for habitually consumed products would result in weight loss compared with matched regular products and that this would impact on markers of vascular health, glycemia and lipemia in healthy normal to overweight men and women. Indeed, preventative public health strategies that target healthy populations by addressing behavioral risk factors such as unhealthy dietary practices, including the high consumption of dietary sugars, could be effective approaches for promoting health and preventing cardiometabolic disease progression [21].

\section{Experimental methods}

\section{Participants}

The REFORM study included men $(n=16)$ and women $(n=34)$ aged 20-49 year who were not underweight or obese (BMI between 18.5 and $30 \mathrm{~kg} / \mathrm{m}^{2}$ ) who were recruited from the local community of Reading, UK, in one cohort between March and September 2012. The intervention visits ran between May 2012 and March 2013. Recruitment strategies included targeted mailings to volunteers on local participant databases. Posters and flyers were circulated around the university campus as well as social and community groups in the Reading area. Key exclusion criteria were as follows: clinical diagnosis of diabetes, CVD, anti-inflammatory or hypertensive medication, smoking, excessive alcohol consumption ( $>21$ units per week for men and $>14$ units per week for women), participation in regular vigorous exercise or fitness training ( $\geq 20 \mathrm{~min} \times 3$ times/week), pregnancy or lactating. The Joint British Societies' JBS-2 total CVD risk calculator was used to estimate the probability (percentage chance) that a participant would experience a CVD event over the next 10-year period [22]. Dietary restraint was quantified using the Three-Factor Eating Questionnaire, with a score $>11$ (Factor I) indicating restrained eating [23, 24]; this score was used to characterize the cohort, but it was not used as an exclusion criteria for study participation.

Participants were not aware that the primary outcome of the study was body weight, as this could have influenced the study outcome. They were told that the purpose of the study was to examine the effect of reformulated fat, salt or sugar-reduced beverage and food items on risk factors for CVD. All procedures involving human participants were approved by the University of Reading's Research Ethics Committee (12/03). Written informed consent was obtained from all participants before participation. The REFORM study was registered a clinical trial (Clinicaltrials.Gov ID: NCT01645995). 
Table 1 REFORM food exchange model: removal of major exchangeable sources of dietary sugar in the UK diet and replacement of exchangeable sugar with REFORM study beverages and foods

\begin{tabular}{|c|c|c|c|c|c|c|}
\hline & Mean quantity (g/day) & Energy (kcal/day) & $\mathrm{CHO}$ (g/day) & Total sugars (g/day) & NMES (g/day) & Starch (g/day) \\
\hline NDNS intake $^{\mathrm{a}}$ & & 1918 & 227.0 & 99.3 & 62.1 & 127.8 \\
\hline \multicolumn{7}{|l|}{ Exchangeable sugar intake } \\
\hline Breakfast cereals & 19 & 47 & 7.8 & 3.7 & 1.5 & 5.3 \\
\hline Puddings & 12 & 19 & 2.3 & 1.5 & 1.3 & 0.4 \\
\hline Vegetables (baked beans) & 93 & 42 & 9.1 & 3.4 & 1.5 & 4.6 \\
\hline $\begin{array}{l}\text { Sugar, preserves and confection- } \\
\text { ary }\end{array}$ & -24 & 100 & 15.9 & 18.2 & 13.9 & 0.0 \\
\hline $\begin{array}{l}\text { Yoghurts, ice cream and other } \\
\text { milks }\end{array}$ & 38 & 58 & 4.5 & 3.0 & 2.4 & 0.3 \\
\hline Soft drinks and fruit juice & 199 & 46 & 15.9 & 17.4 & 15.2 & 0.0 \\
\hline Savory sauces and condiments & 22 & 38 & 2.3 & 4.7 & 1.5 & 3.0 \\
\hline Total exchangeable sugar intake & & 350 & 57.8 & 51.9 & 37.3 & 13.6 \\
\hline $\begin{array}{l}\text { NDNS intake-total exchange- } \\
\text { able sugar (Non-modifiable } \\
\text { sugar intake) }\end{array}$ & & 1568 & 169 & 47.4 & 24.8 & 114.2 \\
\hline \multicolumn{7}{|l|}{ Regular dietary exchange } \\
\hline $\begin{array}{l}\text { Study beverage (mean of seven } \\
\text { choices) })^{\mathrm{b}}\end{array}$ & 315 & 160 & 37.7 & 37.6 & 37.7 & 0.1 \\
\hline $\begin{array}{l}\text { Study food (mean of fifteen } \\
\text { choices) })^{\mathrm{b}}\end{array}$ & 74 & 107 & 18.5 & 14.7 & 12.6 & 3.8 \\
\hline Total intake & 389 & 1835 & 225.2 & 99.7 & 75.1 & 118.1 \\
\hline \multicolumn{7}{|l|}{ Reformulated dietary exchange } \\
\hline $\begin{array}{l}\text { Study beverage (mean of seven } \\
\text { choices) }^{\mathrm{b}}\end{array}$ & 315 & 17 & 2.0 & 1.9 & 1.9 & 0.0 \\
\hline $\begin{array}{l}\text { Study food (mean of fifteen } \\
\text { choices) })^{\mathrm{b}}\end{array}$ & 73 & 75 & 11.7 & 3.1 & 2.2 & 4.6 \\
\hline Total intake & 388 & 1660 & 182.7 & 52.4 & 28.9 & 118.8 \\
\hline $\begin{array}{l}\text { Mean difference between dietary } \\
\text { exchanges }\end{array}$ & & 175 & 42.5 & 47.3 & 46.2 & -0.7 \\
\hline
\end{tabular}

CHO carbohydrate, NMES non-milk extrinsic sugars

a Based on National Diet and Nutrition Survey (NDNS), 2003 for adults (19-64 year) [27]

b Quantity varied depending on the study beverage or food. The replacement model was based on 1 beverage and 1 food per day and excluded ad libitum intake of condiments

\section{Study design}

The REFORM study was performed using a randomized, controlled, double-blind, crossover design and consisted of two 8-week dietary exchange intervention periods. Participants attended the Hugh Sinclair Unit of Human Nutrition on four separate occasions (before and after the two intervention phases). A computer-based minimization procedure (minimized on age, gender, BMI) was used to randomly allocate participants to consume either regular or sugar-reduced products (i.e., diet A or diet B) during their first 8-week dietary exchange period [25]. This was subsequently followed by a 4-week washout period after which the participants began the alternate study intervention.
Participants were advised prior to each visit to avoid strenuous physical activity (PA) and alcohol consumption for a 24-h period. Following a standardized low-fat evening meal ( $<400 \mathrm{kcal} ;<9 \mathrm{~g}$ fat), participants completed a $12-\mathrm{h}$ fast.

\section{Dietary exchange model}

For the REFORM dietary intervention, a flexible food exchange model, based on average UK food intake data of adults aged 19-64 year, was developed using a well-established approach that allows for minimal disruption to the habitual diet of free-living individuals [26]. The amount of exchangeable sugar in the free-living UK diet was 
calculated from the NDNS database [27] as the total NMES present in the following easily accessible food sources: breakfast cereals, baked beans, puddings, chocolate, sweet confectionary, sweet spreads, savory sauces, condiments, soft drinks, fruit juice, yoghurt, ice cream and other milks (Table 1). It was estimated that $60 \%$ of the sugar-containing processed foods and beverages could be exchanged so as to manipulate the overall NMES composition of the habitual diet. Commercially available regular and sugarreduced products, with a specific NMES profile, were tested in the dietary exchange model; it was quantified that the minimum daily NMES difference between the regular and reformulated dietary exchange periods was $32 \mathrm{~g} / \mathrm{day}$, with the reformulated arm consuming $<7 \%$ EI as NMES.

\section{Dietary exchange intervention and compliance monitoring}

For each 8-week dietary exchange period, participants exchanged $\geq 1$ beverage and $\geq 1$ food portion per day from their habitual diet with equivalent sugar-containing or sugar-reformulated products (for details of study foods, see Online Resource 1). After completing baseline study visits (at the beginning of each dietary assessment period), participants were given personalized advice about the dietary exchange intervention and how to incorporate the study products into their diet. Participants were given adequate study product supplies for a 4-week period at the beginning of each dietary assessment period. They also attended the Hugh Sinclair Unit of Human Nutrition for a food collection visit and dietary compliance assessment at week 4, the midway point in each dietary exchange period. During this visit, completed compliance sheets were assessed and any issues with dietary adherence were addressed and rectified. To encourage dietary adherence and reduce the likelihood of 'product boredom' [26], participants were provided with sufficient study products from a choice of 7 beverages including juice drinks and soft drinks, and 19 foods, including pasta sauce, baked beans, muesli, puddings and sweet confectionary (for details, see Online Resource 1). Participants were asked to replace habitually used sugar and condiments with those provided by the investigators ad libitum throughout the dietary exchange periods (Online Resource 1). Study product selection was based on each participants' response to a food preference screening list that itemized the beverage, food, sugar and condiments options that were available to them as part of the dietary exchange intervention. They were asked to consume similar types of REFORM beverages/foods during their second arm of the study so that the regular and reformulated product types would be matched. Participants completed a daily dietary compliance sheet to assess their intake of the study products during the two 8-week dietary assessment periods (i.e., for a 56-day period). At the end of the first diet period, participants were asked to return unopened leftover products to the Nutrition Unit. They were instructed not to consume leftover study products during their washout period and were advised to return to their habitual diet.

Study products were presented to volunteers in a blinded manner. An investigator not involved with assessing study outcomes de-branded, relabeled or repackaged the study products so that they appeared identical between interventions, with the two dietary exchange products identifiable by diet A or B. The minimum beverage or food portion size was stated by weight and in general household measures.

\section{Assessment of intervention foods and blinding strategy}

At the end of each 8-week dietary period, the study products were assessed for visual appeal, smell, taste, aftertaste and palatability using visual analogue scale (VAS) questionnaires [28]. Each VAS assessed a sensation on a 100$\mathrm{mm}$ horizontal line, anchored at the beginning and end by opposing statements. On completion of the study, a retrospective questionnaire assessed participants' perceived awareness of the order in which they had been assigned to the regular and reformulated study products.

\section{Assessment of dietary intake}

Four-day weighed food diaries were completed prior to commencing and during the final week of the dietary exchange periods (week $0,8,12,20$ ). Participants completed their food diaries over three weekdays and one weekend day, with the same days repeated for subsequent food diaries. Detailed verbal and written instructions for completing their 4-day weighed food diaries were given to participants $\geq 7$ days prior to their first study visit. A set of sample diaries and a set of digital scales were also provided, and the importance of not changing habitual dietary patterns was emphasized. Participants were asked to record recipes used during cooking and retain packaging from ready meals so that the items could be added to the dietary database. During study visits, food diaries were assessed for completeness. If necessary, further detail was collected to facilitate precise data entry.

Dietplan software (version 6.60; Forestfield Software Ltd.) was used to calculate specific energy and macronutrient intake. The nutrient composition of foods consumed was based on NDS Nutrient Database or McCance and Widdowson's food tables. Dietary fiber intake was defined as non-starch polysaccharide (NSP) using the technique of Englyst and Cummings [29]. The composition of the study products was also added to Dietplan, based on manufacturer details. 


\section{Assessment of physical activity}

Participants were instructed to wear a triaxial accelerometer (GT3X + activity monitor; Actigraph, LLC) directly above the right iliac crest during sleeping and waking hours (except during water-based activities) for seven consecutive days, over the same time period that dietary intake was assessed. Device initialization, data processing and analysis were conducted using Actilife data analysis software (version 6.4.5). For analysis inclusion, participants were required to have produced counts on their activity monitor for $\geq 4$ days ( $>600 \mathrm{~min} /$ day of wear time) [30]. Non-wear time was defined as $\geq 60$ min of zero activity counts [31]. Data were summarized in 60 -sec epochs, and mean EE from PA $\left(\mathrm{EE}_{\mathrm{PA}}\right)$ was calculated (kcal/day). Total daily step count, based on accelerometry, was also calculated and was used to estimate PA levels with $<5000,5000-7400,7500$ 9999 and 10,000 steps/day categorizing participants as sedentary, low active, somewhat active and active, respectively $[32,33]$.

\section{Basal metabolic rate}

Basal metabolic rate (BMR) for each participant was calculated based on age, gender and body weight using the Henry equation [34].

\section{Body weight}

Upon arrival at the Nutrition Unit, height was measured to the nearest $0.1 \mathrm{~cm}$ using a wall-mounted stadiometer (first visit only). While wearing light garments, body mass $(\mathrm{kg})$ and body fat (\%) were assessed by Tanita Body Composition Analyzer (BC-418 MA; Ill, USA) using standard settings (normal adult body type and $1 \mathrm{~kg}$ for clothing) at week $0,8,12$ and 20 .

\section{Blood pressure and arterial stiffness}

Participants rested semi-recumbent in a temperature-controlled vascular suite $\left(22 \pm 1{ }^{\circ} \mathrm{C}\right)$. After a 20 -min rest and familiarization period, $\mathrm{BP}$ was recorded in triplicate using an ambulatory upper arm BP monitor (ABPM TM-243; A\&D Instruments Ltd.). Digital volume pulse (DVP) and pulse wave analysis (PWA) were assessed as markers of vascular stiffness. DVP was determined by placing a photoplethysmographic transducer on the left index finger (Pulse Trace PCA 2 device; Micro Medical Ltd.). Measurements were taken in triplicate for calculation of mean reflection index (DVP-RI) and stiffness index (DVP-SI) [35]. PWA was carried out by a single trained operator using the SphygmoCor (ScanMed Medical; see [36] for details). The pulse pressure wave at the radial artery was recorded using applanation tonometry [37]. The mean of two values with the highest operator index $(\geq 80)$ was averaged to calculate the augmentation index (AIx), a measure of overall systemic arterial stiffness and AIx adjusted to a standard HR of $75 \mathrm{bpm}$ (AIx HR75).

\section{Blood sampling and biochemical analysis}

Venous blood samples were collected and centrifuged at $3000 \mathrm{rpm}$ for $15 \mathrm{~min}$ at $4{ }^{\circ} \mathrm{C}$. Serum and plasma were separated and stored at $-80{ }^{\circ} \mathrm{C}$ until subsequent analysis. Concentrations of serum lipids [total cholesterol, high-density lipoprotein cholesterol and triacylglycerol (TAG)], C-reactive protein, non-esterified fatty acid and glucose were determined using enzyme-based colorimetric tests on an ILab 600 Clinical Chemistry Analyzer (Instrumentation Laboratories Ltd.). The ratio of total:HDL cholesterol was calculated. LDL cholesterol concentrations were measured according to the Friedewald equation [38]. Plasma insulin concentrations were determined with enzyme immunoassay kits (Alere Ltd.). Samples from each participant were analyzed in a single run to minimize inter-batch variation.

\section{Energy intake and body weight simulation tool}

For each participant, baseline variables including height, weight, age and gender were entered into the NIDDK human body weight simulation tool [16]. PA level, predicted from mean daily step count categories which were coded to match corresponding activity levels 1.4, 1.5, 1.6 and 1.9 in model $[16,33]$, was also entered. Collectively, these variables were used to provide a prediction of baseline EI (kcal/day).

For the body weight simulation, it was a required assumption that the PA level remained constant for the duration of each dietary exchange period. For body weight simulation, the value of $181 \mathrm{kcal} /$ day was chosen to represent the mean energy deficit of the group during the reformulated dietary exchange period. This was calculated from the average of each participant's 56-day caloric difference between the regular and reformulated dietary exchange periods (Online Resource 2). The energy deficit value was subtracted from the predicted baseline EI and predicted weight, after a 56-day body weight simulation was recorded. For body weight simulation following the regular dietary exchange period, it was assumed that EI remained constant, i.e., the same as that predicted at baseline.

\section{Power calculation}

Power calculations were based on body weight, our primary outcome measure. An estimated weight loss of $1.2 \mathrm{~kg}$ 
was predicted with a daily conservative target difference of $181 \mathrm{kcal} /$ day between the regular and reformulated dietary exchange phases for an 8-week period. The SD of weight reduction was estimated as $1.1 \mathrm{~kg}$. Based on a previous calculation [39], an estimated recruitment of $n=37$ participants was deemed necessary to give sufficient power to detect significant changes in our secondary outcome measures including biochemical analysis, if energy compensation did not occur, with $P<0.05$ and $80 \%$ power. With the allowance for a $25 \%$ dropout rate, we aimed to recruit a minimum of 47 participants.

\section{Statistical analysis}

All statistical analysis was performed on primary (body weight) and secondary outcome measures using SPSS (version 19.0; SPSS Inc.). Data that were not normally distributed, as assessed by the Shapiro-Wilk test, were logarithmically transformed. The potential impact of an intervention order was assessed by adding it as a main effect to our repeated measures ANOVA model. However, because no significant interactions between intervention order and our other main effects (time and diet) were detected, a two-way

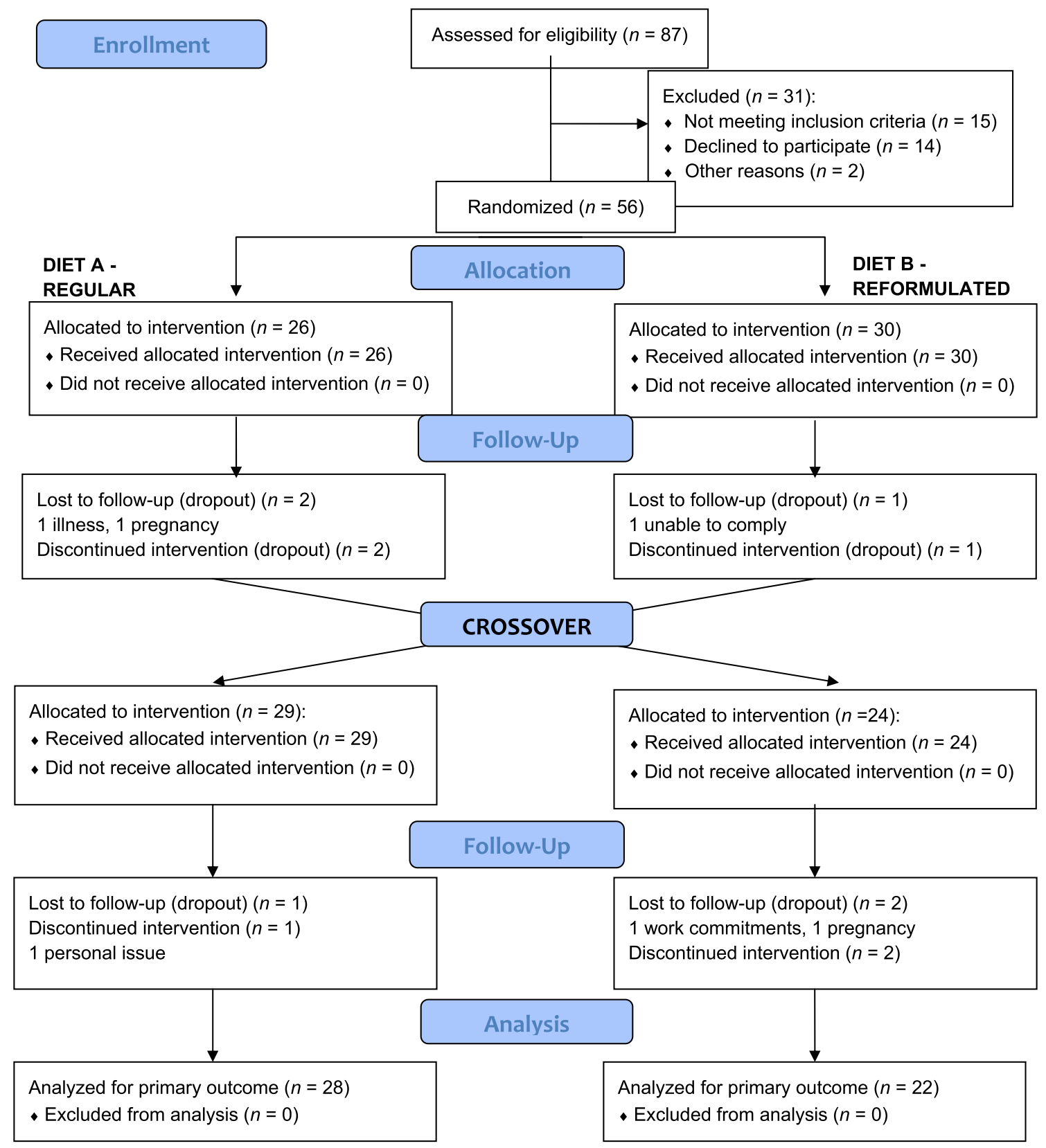

Fig. 1 Flow of participants through the different stages of the REFORM study 
ANOVA was used to identify significant time $X \operatorname{diet}(T \mathrm{X} D)$ interactions. Bonferroni post hoc corrections were applied to all data to control for multiple comparisons. For our primary outcome measure, multiple adjustments were made for age, gender and dietary restraint using a two-way ANCOVA. The association between observed and predicted (using the body weight simulation model [33]) body weights was analyzed using Pearson's correlations. Paired $t$ tests were used to compare dietary compliance data. Differences in baseline characteristics between participants randomly assigned to the regular and reformulated dietary exchange arms were assessed by using the independent $t$ tests and the Chi square test for continuous and categorical variables, respectively (Online Resource 3). Data are presented as mean \pm SD. $P$ values $<0.05$ were deemed to be significant.

\section{Results}

\section{Participants}

Participant flow through the study is illustrated in Fig. 1. In total, 87 individuals were screened; 56 were recruited to the study and 50 participants ( $n=40$ White; $n=9$ Asian; $n=1$ Black) completed all four study visits. Both dietary exchange periods were well tolerated by participants, and no adverse events were reported. The baseline characteristics of the participants are highlighted in Table 2. Overall, participants had a $1.8 \pm 3.4 \%$ chance of developing CVD risk over the next 10 -year period using the JBS-2 total CVD risk calculator [22]. Mean dietary restraint scores were $6.6 \pm 4.2$, with nine participants identified as restrained eaters. Five participants were excluded from the $\mathrm{EI}$ and $\mathrm{EE}_{\mathrm{PA}}$ analysis due to insufficient data.

\section{Energy and macronutrient intake}

Mean habitual diets reported by the participants at baseline were comparable to representative dietary values for UK adults [9]. NMES intake fell to a mean of $8.3 \%$ EI, meeting the criteria of $\leq 10 \%$ EI on the sugar-reformulated diet. As a \% EI, carbohydrate $(P<0.001)$, total sugars $(P<0.001)$ and NMES $(P<0.001)$ were lower, whereas fat $(P=0.001)$ and protein $(P=0.038)$ were higher on the sugar-reduced diet compared with the regular diet (Table 3).

\section{Body weight and energy balance dynamics}

There was no significant interaction for our primary outcome measure, body weight or percentage body fat, or for $\mathrm{EI}, \mathrm{EE}_{\mathrm{PA}}$ or $\mathrm{EE}_{\mathrm{BMR}}$ (Table 4). Further analysis revealed that there was no significant impact of the intervention on body weight when it was adjusted for multiple
Table 2 Baseline characteristics of 50 participants who completed the intervention ${ }^{\mathrm{a}}$

\begin{tabular}{|c|c|}
\hline Parameter & \\
\hline \multicolumn{2}{|l|}{ Gender $[n(\%)]$} \\
\hline M & $16(32)$ \\
\hline $\mathrm{F}$ & $34(68)$ \\
\hline Age (year) & $31.6 \pm 9.5$ \\
\hline Body weight (kg) & $69.8 \pm 11.4$ \\
\hline BMI $\left(\mathrm{kg} / \mathrm{m}^{2}\right)$ & $24.0 \pm 3.3$ \\
\hline Body fat $(\%)$ & $27.0 \pm 9.6$ \\
\hline Supine systolic blood pressure (mmHg) & $116 \pm 11$ \\
\hline Supine diastolic blood pressure $(\mathrm{mmHg})$ & $71 \pm 8$ \\
\hline Glucose (mmol/L) & $4.85 \pm 0.42$ \\
\hline Insulin $(\mathrm{pmol} / \mathrm{L})^{\mathrm{b}}$ & $31.0 \pm 14.3$ \\
\hline Total cholesterol (mmol/L) & $4.63 \pm 0.71$ \\
\hline HDL cholesterol (mmol/L) & $1.50 \pm 0.37$ \\
\hline Total: HDL cholesterol ratio & $3.22 \pm 0.77$ \\
\hline LDL cholesterol (mmol/L) & $2.71 \pm 0.61$ \\
\hline Triacylglycerol (mmol/L) & $0.93 \pm 0.39$ \\
\hline $\mathrm{EI}(\mathrm{kcal} / \mathrm{day})^{\mathrm{c}}$ & $2078 \pm 675$ \\
\hline $\mathrm{EE}_{\mathrm{PA}}(\mathrm{kcal} / \mathrm{day})^{\mathrm{c}}$ & $446 \pm 157$ \\
\hline Mean accelerometer wear time (min/day) & $1187 \pm 128$ \\
\hline Number of steps (counts/day) ${ }^{\mathrm{c}}$ & $9064 \pm 261$ \\
\hline
\end{tabular}

$B M I$ body mass index, $E E_{P A}$ energy expenditure from physical activity assessed by triaxial accelerometry, $E I$ energy intake, $H D L$ highdensity lipoprotein, $L D L$ low-density lipoprotein

a Values are presented as mean $\pm \mathrm{SD}$

b $n=48$

c $n=45$

covariates including age, gender and dietary restraint (time: $P=0.556$; diet: $P=0.312$; time $x$ diet interaction: $P=0.203)$.

\section{Energy intake and body weight prediction model}

Using the NIDDK mathematical model [16], predicted EI at baseline and post-intervention was calculated. The baseline predicted EI did not differ significantly between the regular and reformulated dietary exchange periods (Regular $2420 \pm 385$; Reformulated $2410 \pm 389 \mathrm{kcal} /$ day; $P=0.443$ ). A mean of 79.2 and $80.8 \%$ of predicted EI was reported from dietary analysis by participants prior to the regular and reformulated dietary exchange periods, but there was no significant difference in the baseline levels of under-reporting between the two dietary periods $(P=0.786)$. We observed a significant association between the predicted and observed body weight following the regular $(r=0.993, P<0.001)$ and reformulated dietary exchange periods $(r=0.994, P<0.001)$. The arithmetic difference between the predicted and 
Table 3 Daily energy and macronutrient intake at baseline (pre-) and during week-7 (post-) of the regular or reformulated dietary exchange period $^{\mathrm{a}, \mathrm{b}}$

\begin{tabular}{|c|c|c|c|c|c|}
\hline & \multirow[t]{2}{*}{ Regular } & \multirow[t]{2}{*}{ Reformulated } & \multicolumn{3}{|c|}{$P$ values } \\
\hline & & & $T$ & $D$ & $T \times D$ \\
\hline EI (kcal/day) & & & 0.201 & 0.208 & 0.075 \\
\hline Pre- & $1895 \pm 568$ & $1916 \pm 553$ & & & \\
\hline Post- & $2049 \pm 529$ & $1887 \pm 546$ & & & \\
\hline Protein $(\% \mathrm{EI})^{\mathrm{c}}$ & & & 0.383 & $<0.001$ & 0.038 \\
\hline Pre- & $16.4 \pm 3.8$ & $16.3 \pm 3.8$ & & & \\
\hline Post- & $14.3 \pm 2.6$ & $15.4 \pm 3.2$ & & & \\
\hline Fat (\% EI) & & & 0.180 & 0.003 & 0.001 \\
\hline Pre- & $33.9 \pm 5.4$ & $32.3 \pm 6.5$ & & & \\
\hline Post- & $29.6 \pm 6.1$ & $32.8 \pm 6.3$ & & & \\
\hline $\mathrm{CHO}(\% \mathrm{EI})$ & & & 0.007 & $<0.001$ & $<0.001$ \\
\hline Pre- & $47.3 \pm 6.7$ & $49.2 \pm 6.9$ & & & \\
\hline Post- & $54.2 \pm 7.3$ & $48.2 \pm 7.8$ & & & \\
\hline $\begin{array}{l}\text { Total sugars } \\
(\% \mathrm{EI})^{\mathrm{c}}\end{array}$ & & & 0.000 & 0.314 & $<0.001$ \\
\hline Pre- & $20.6 \pm 6.6$ & $21.8 \pm 7.3$ & & & \\
\hline Post- & $28.0 \pm 7.0$ & $17.1 \pm 6.1$ & & & \\
\hline Starch (\% EI) & & & 0.871 & 0.400 & 0.786 \\
\hline Pre- & $25.6 \pm 6.3$ & $25.8 \pm 6.2$ & & & \\
\hline Post- & $24.6 \pm 5.6$ & $27.1 \pm 7.1$ & & & \\
\hline NMES (\% EI) & & & $<0.001$ & 0.003 & $<0.001$ \\
\hline Pre- & $10.5 \pm 5.0$ & $11.0 \pm 6.2$ & & & \\
\hline Post- & $19.7 \pm 5.6$ & $8.3 \pm 4.7$ & & & \\
\hline $\begin{array}{l}\text { Fiber intake }(\mathrm{g} / \\
\text { day })^{\mathrm{c}}\end{array}$ & & & 0.512 & 0.005 & 0.638 \\
\hline Pre- & $15.0 \pm 6.9$ & $14.9 \pm 6.5$ & & & \\
\hline Post- & $16.1 \pm 6.1$ & $16.6 \pm 5.6$ & & & \\
\hline
\end{tabular}

CHO carbohydrate, $D$ diet, $E I$ energy intake, NMES non-milk extrinsic sugars, $T$ time, $T X D$ time $\mathrm{X}$ diet

a Values are presented as mean $\pm \mathrm{SD}$

b $n=45$

c Data were log transformed

observed body weight differed significantly following the 8 -week regular and reformulated dietary exchange periods (Regular $0.9 \pm 1.3 \mathrm{~kg}$; Reformulated $-1.5 \pm 1.2 \mathrm{~kg}$; $P<0.001)$.

\section{Blood pressure and arterial stiffness}

There were no significant differences in systolic or diastolic BP between treatments (Table 5). Furthermore, no significant interactions were observed for DVP-SI, DVP-RI, AIx or AIx HR75 (Table 5).
Table 4 Energy balance dynamics and body composition at baseline (pre-) and at 8 weeks (post-) after random assignment to a regular or reformulated dietary exchange period ${ }^{\mathrm{a}, \mathrm{b}}$

\begin{tabular}{|c|c|c|c|c|c|}
\hline & \multirow[t]{2}{*}{ Regular } & \multirow[t]{2}{*}{ Reformulated } & \multicolumn{3}{|c|}{$P$ values } \\
\hline & & & $T$ & $D$ & $T \mathrm{X} D$ \\
\hline EI (kcal/day) & & & 0.201 & 0.208 & 0.075 \\
\hline Pre- & $1895 \pm 568$ & $1916 \pm 553$ & & & \\
\hline Post- & $2049 \pm 529$ & $1887 \pm 546$ & & & \\
\hline $\mathrm{EE}_{\mathrm{PA}}(\mathrm{kcal} /$ day $)$ & & & 0.738 & 0.014 & 0.970 \\
\hline Pre- & $432 \pm 166$ & $436 \pm 169$ & & & \\
\hline Post- & $419 \pm 201$ & $405 \pm 149$ & & & \\
\hline $\mathrm{EE}_{\mathrm{BMR}}(\mathrm{kcal} / \mathrm{day})^{\mathrm{e}}$ & & & 0.666 & 0.136 & 0.631 \\
\hline Pre- & $1483 \pm 206$ & $1479 \pm 210$ & & & \\
\hline Post- & $1489 \pm 204$ & $1489 \pm 206$ & & & \\
\hline Weight $(\mathrm{kg})^{\mathrm{c}}$ & & & 0.448 & 0.035 & 0.251 \\
\hline Pre- & $69.8 \pm 11.5$ & $70.1 \pm 11.3$ & & & \\
\hline Post- & $70.3 \pm 11.3$ & $70.2 \pm 11.4$ & & & \\
\hline BMI $\left(\mathrm{kg} / \mathrm{m}^{2}\right)^{\mathrm{c}, \mathrm{d}}$ & & & 0.300 & 0.401 & 0.202 \\
\hline Pre- & $24.0 \pm 3.4$ & $24.1 \pm 3.3$ & & & \\
\hline Post- & $24.1 \pm 3.3$ & $24.1 \pm 3.4$ & & & \\
\hline Body fat $(\%)^{\mathrm{c}}$ & & & 0.222 & 0.447 & 0.541 \\
\hline Pre- & $26.9 \pm 9.6$ & $27.2 \pm 9.4$ & & & \\
\hline Post- & $27.1 \pm 9.2$ & $27.3 \pm 9.4$ & & & \\
\hline
\end{tabular}

$B M I$ body mass index, $D$ diet, $E E_{B M R}$ energy expenditure by basal metabolic rate, $E I$ energy intake, $E E_{P A}$ energy expenditure from physical activity assessed by triaxial accelerometry, $T$ time, $T$ XD time $\mathrm{X}$ diet

a Values are presented as mean $\pm \mathrm{SD}$

b $n=45$

c $n=50$

d Data were log transformed

e Estimated with an equation including age, gender and body weight [34]

\section{Biochemical parameters}

There were no significant changes in biochemical parameters following the regular compared with the reformulated products (Table 5).

\section{Assessment of dietary compliance, intervention foods and blinding strategy}

The mean caloric and NMES differences between the regular and reformulated dietary exchange periods, inclusive of sugar and condiments, that were calculated for the two complete 8-week dietary assessment periods were $181 \mathrm{kcal} /$ day and $54.4 \mathrm{~g} /$ day, respectively (see Online Resource 3 for dietary compliance data) with significantly higher intakes 
Table 5 Blood pressure, arterial stiffness measurements and biochemical parameters at baseline (pre-) and at 8 weeks (post) after random assignment to a regular or reformulated dietary exchange period ${ }^{\mathrm{a}, \mathrm{b}}$

\begin{tabular}{|c|c|c|c|c|c|}
\hline \multirow[b]{2}{*}{ Parameter } & \multirow[b]{2}{*}{ Regular } & \multirow[b]{2}{*}{ Reformulated } & \multicolumn{3}{|c|}{$P$ values } \\
\hline & & & $\mathrm{T}$ & $\mathrm{D}$ & $T X D$ \\
\hline Supine systolic blood pressure $(\mathrm{mmHg})^{\mathrm{e}}$ & & & 0.813 & 0.188 & 0.518 \\
\hline Pre- & $116 \pm 11$ & $116 \pm 12$ & & & \\
\hline Post- & $116 \pm 11$ & $115 \pm 12$ & & & \\
\hline Supine diastolic blood pressure (mmHg) & & & 0.113 & 0.970 & 0.844 \\
\hline Pre- & $71 \pm 7$ & $72 \pm 8$ & & & \\
\hline Post- & $71 \pm 8$ & $72 \pm 8$ & & & \\
\hline Digital volume pulse stiffness index $(\mathrm{m} / \mathrm{s})^{\mathrm{c}}$ & & & 0.416 & 0.099 & 0.477 \\
\hline Pre- & $5.5 \pm 0.7$ & $5.5 \pm 0.6$ & & & \\
\hline Post- & $5.5 \pm 0.6$ & $5.6 \pm 0.7$ & & & \\
\hline Digital volume pulse reflection index $(\%)^{\mathrm{c}}$ & & & 0.477 & 0.132 & 0.752 \\
\hline Pre- & $55.5 \pm 12.1$ & $56.6 \pm 11.6$ & & & \\
\hline Post- & $57.7 \pm 10.7$ & $58.1 \pm 13.2$ & & & \\
\hline Pulse wave analysis augmentation index $(\%)^{\mathrm{e}}$ & & & 0.198 & 0.259 & 0.234 \\
\hline Pre- & $13.9 \pm 11.6$ & $14.2 \pm 13.1$ & & & \\
\hline Post- & $14.2 \pm 11.7$ & $15.1 \pm 13.4$ & & & \\
\hline $\begin{array}{l}\text { Pulse wave analysis augmentation index adjusted to a } \\
\text { standard HR of } 75 \mathrm{bpm}(\%)\end{array}$ & & & 0.442 & 0.400 & 0.736 \\
\hline Pre- & $6.3 \pm 12.1$ & $5.2 \pm 14.2$ & & & \\
\hline Post- & $6.8 \pm 12.3$ & $7.3 \pm 13.8$ & & & \\
\hline Glucose (mmol/L) & & & 0.611 & 0.010 & 0.220 \\
\hline Pre- & $4.86 \pm 0.40$ & $4.84 \pm 0.42$ & & & \\
\hline Post- & $4.90 \pm 0.45$ & $4.95 \pm 0.39$ & & & \\
\hline Insulin $(\mathrm{pmol} / \mathrm{L})^{\mathrm{d}, \mathrm{e}}$ & & & 0.185 & 0.072 & 0.665 \\
\hline Pre- & $34.9 \pm 20.4$ & $33.6 \pm 18.9$ & & & \\
\hline Post- & $37.6 \pm 20.5$ & $35.2 \pm 20.4$ & & & \\
\hline Total cholesterol $(\mathrm{mmol} / \mathrm{L})^{\mathrm{e}}$ & & & 0.653 & 0.352 & 0.021 \\
\hline Pre- & $4.67 \pm 0.70$ & $4.57 \pm 0.69$ & & & \\
\hline Post- & $4.59 \pm 0.65$ & $4.58 \pm 0.67$ & & & \\
\hline HDL cholesterol $(\mathrm{mmol} / \mathrm{L})^{\mathrm{e}}$ & & & 0.359 & 0.500 & 0.067 \\
\hline Pre- & $1.54 \pm 0.38$ & $1.50 \pm 0.37$ & & & \\
\hline Post- & $1.51 \pm 0.38$ & $1.51 \pm 0.34$ & & & \\
\hline Total:HDL cholesterol ratio ${ }^{\mathrm{e}}$ & & & 0.672 & 0.993 & 0.457 \\
\hline Pre- & $3.17 \pm 0.76$ & $3.17 \pm 0.74$ & & & \\
\hline Post- & $3.18 \pm 0.76$ & $3.14 \pm 0.70$ & & & \\
\hline LDL cholesterol $(\mathrm{mmol} / \mathrm{L})^{\mathrm{e}}$ & & & 0.338 & 0.387 & 0.360 \\
\hline Pre- & $2.74 \pm 0.61$ & $2.66 \pm 0.58$ & & & \\
\hline Post- & $2.67 \pm 0.55$ & $2.66 \pm 0.56$ & & & \\
\hline Triacylglycerol $(\mathrm{mmol} / \mathrm{L})^{\mathrm{e}}$ & & & 0.954 & 0.460 & 0.419 \\
\hline Pre- & $0.88 \pm 0.37$ & $0.90 \pm 0.37$ & & & \\
\hline Post- & $0.92 \pm 0.38$ & $0.91 \pm 0.41$ & & & \\
\hline Non-esterified fatty acid $(\mu \mathrm{mol} / \mathrm{L})^{\mathrm{e}}$ & & & 0.704 & 0.044 & 0.898 \\
\hline Pre- & $464.5 \pm 164.3$ & $473.9 \pm 176.2$ & & & \\
\hline
\end{tabular}


Table 5 continued

\begin{tabular}{|c|c|c|c|c|c|}
\hline \multirow[b]{2}{*}{ Parameter } & \multirow[b]{2}{*}{ Regular } & \multirow[b]{2}{*}{ Reformulated } & \multicolumn{3}{|c|}{$P$ values } \\
\hline & & & $\mathrm{T}$ & $\mathrm{D}$ & $T \times D$ \\
\hline Post- & $443.3 \pm 189.7$ & $436.5 \pm 170.4$ & & & \\
\hline C-reactive protein $(\mathrm{mg} / \mathrm{L})^{\mathrm{e}}$ & & & 0.547 & 0.581 & 0.593 \\
\hline Pre- & $0.93 \pm 0.94$ & $1.05 \pm 1.35$ & & & \\
\hline Post- & $0.99 \pm 1.03$ & $1.21 \pm 1.50$ & & & \\
\hline
\end{tabular}

$D$ diet, $H D L$ high-density lipoprotein, $L D L$ low-density lipoprotein, $T$ time, $T$ X $D$ time $\mathrm{X}$ diet

a Values are presented as mean $\pm \mathrm{SD}$

b $n=50$

c $n=47$

d $n=48$

e Data were log transformed

of NMES after the regular (Pre- $52.4 \pm 35.8$ g/day, Post$98.9 \pm 34.0 \mathrm{~g} / \mathrm{day}$ ), when compared with the reformulated arm (Pre- $54.3 \pm 36.4$ g/day, Post- $37.8 \pm 19.9$ g/ day; $P<0.001)$. These values were higher than our target difference in NMES intake as calculated using the dietary exchange model (Table 1) and provide evidence that the dietary objectives of REFORM were successfully met and exceeded.

Lower mean ratings of taste $(23.0 \pm 10.8$ vs $28.9 \pm 11.6 \mathrm{~mm} ; P<0.001)$ and palatability $(23.7 \pm 11.2$ vs $28.2 \pm 12.5 \mathrm{~mm} ; P=0.009)$ of the reformulated compared with the regular products were observed. Visual appeal, smell and aftertaste of the products did not vary significantly between treatments (data not shown). A total of $83 \%$ of all participants correctly identified the regular and reformulated products.

\section{Discussion}

The REFORM randomized controlled trial is the first to examine the impact of sugar-reformulated food and beverage consumption on the dynamics of body weight, EB, BP, arterial stiffness, serum glucose and lipid concentrations in normal to overweight free-living adults [BMI mean (range) $\left.23.5(18.4-29.9) \mathrm{kg} / \mathrm{m}^{2}\right]$ in a suitably powered study. We observed that when sugar-reduced foods and beverages were consumed as part of the habitual diet no significant change in body weight was observed. This was due to energy compensation; fat and protein intakes were both higher on the sugar-reduced diet, when compared to the regular diet.

Our cohort was relatively healthy with a generally low risk of developing CVD [22], yet they exceeded UK Department of Health dietary recommendations [8] by consuming $>10 \%$ EI from NMES at baseline. A strength of the REFORM study was the successful implementation of the novel dietary exchange model, resulting in the reduction in dietary targets of NMES, in line with recommendations [8] using both foods and beverages as intervention products. It is relatively simple to reduce the energy content of beverages by directly exchanging sugars with artificial sweeteners (AS). However, in more complex matrices, such as some of the reformulated foods used in our intervention, replacement of sugars with other nutrients such as starch is required to maintain functional properties of the products, and this may result in a smaller reduction in energy content [40]. Due to the inherent challenges of using sugar-reformulated foods in dietary intervention studies, their efficacy is poorly studied. Yet it is fundamental to determine their value as a strategy to reduce dietary sugar and energy for long-term weight control [12]. Specific dietary targets during the exchange periods of our intervention were largely achieved. Using the NIDDK simulation tool [16], body weight was predicted to be lower than observed, between the reformulated and regular dietary exchange periods, with no change in $\mathrm{EE}_{\mathrm{PA}}$ and $\mathrm{EE}_{\mathrm{BMR}}$, supporting our hypothesis of dietary energy compensation. Although the change did not reach statistical significance, EI was lower following the reformulated diet period, and this was matched by lower PA-related EE, suggesting that this may have also contributed to the observed energy compensation. Our study was limited by the fact that we did not use a calorimetric method for determination of EE [41, 42]; therefore, it is possible that small changes in total EE may have also contributed to energy compensation. During the regular arm of the study, it should be noted that participants increased their intake of NMES to $20 \% \mathrm{EI}$, a $9 \%$ increase when compared to baseline. In line with this, the studies of Reid and colleagues highlighted that, regardless of level of adiposity, when given in a blinded manner to free-living women for a 4-week period, SSB supplementation $(4 \times 250 \mathrm{~mL} ; 430 \mathrm{kcal} /$ day $)$ was partially compensated for through voluntary reductions in macronutrient intake 
and hence did not lead to weight gain [33, 43, 44]. Following a 6-month intervention where overweight individuals were randomly assigned to consume either $1000 \mathrm{~mL} /$ day of sugar-sweetened cola, diet cola, semi-skimmed milk or water, Maersk et al. [45] did show that regular cola intake significantly enhanced fat accumulation in the liver, skeletal muscle and visceral fat, with no overall change in total fat or body weight. An increased production of plasma TAG was proposed as one plausible mechanism for the body weight-independent metabolic effect of dietary sugar [45]. Although we did not measure specific organ fat accumulation in the present study, it seems unlikely that we would have observed any changes in this parameter, given the lack of effect on circulating serum TAG.

Consumption of the sugar-reformulated products, in exchange for regular matched products in the REFORM study, did not result in differences in fasting BP, arterial stiffness, glycemia or lipemia. Despite not finding an impact of a 6-week high sucrose diet (25\% EI) on BP, PWA or any metabolic variable, Black and colleagues [19] observed modest increases in total and LDL cholesterol. In addition, during a 10-week sucrose supplementation period ( $\sim \mathrm{g} / \mathrm{kg}$ of body weight), where supplements were mostly given in the form of SSBs, Raben et al. [20] found a significant increase in systolic or diastolic BP compared to a diet rich in AS, while a more recent paper by this group showed that no independent effects on fasting insulin and postprandial TAG concentrations were observed, when data were adjusted for body weight change [46].

Although potential underlying mechanisms responsible for the relationship between added sugar consumption and cardiometabolic risk are not fully established, emerging research suggests that in addition to the indirect impact of weight gain on these parameters, excessive added sugar consumption may impact on several physiological pathways $[47,48]$. When consumed in excess (>20 \% EI), fructose intake has been adversely linked to de novo lipogenesis, BP, visceral and ectopic fat deposition, insulin sensitivity as well as fat oxidation [18, 45, 49], although these levels far exceed current intakes. Furthermore, men and women with a genetic predisposition to obesity had a more pronounced susceptibility to the impact of SSBs on adiposity [50]. Future investigation is necessary to evaluate the differential impact of ethnicity on adiposity and cardiometabolic risk markers in response to regular sugar and sugar-reduced product consumption.

There are possible limitations of the REFORM study. Although sufficiently powered to detect predicted weight changes associated with the energy deficit if $\mathrm{EB}$ was maintained, our intervention period may not have been adequate to identify changes in some secondary outcome measures, including arterial stiffness [51]. Additionally, our dietary exchange provided a realistic dietary sugar intake from consumption of commercially available sugarreformulated foods and beverages, but this resulted in modest differences in sugar intake compared with other studies [18, 20, 33, 43, 44]. Despite this, the body simulation tool [16] predicted that these modest differences in dietary sugar intake were sufficient to detect a difference of $2.4 \pm 1.7 \mathrm{~kg}$ in body weight between the diets. This was not observed and indicates partial compensation for the lower or higher EI during the reformulated or regular dietary arm, respectively, confirming our dietary intake data. We also acknowledge the limitation of estimating EI using self-reported measurements [41], but note that this issue was deemed to be less significant, given that we supplied the regular and sugar-reduced study foods for the participants to consume during their dietary exchange periods and monitored dietary compliance. Furthermore, mean EI predicted by the NIDDK model [33] did not differ between the regular and reformulated dietary exchange periods at baseline.

Evaluation of the efficacy of public health strategies for health promotion is essential. Previous food reformulation strategies targeting salt and trans fatty acid reduction have proven effective [7, 52], while the success of sugar-reformulated products is less clear. Systematic reduction in the sugar content of food stuffs, without any AS substitution, may be a feasible approach to reducing sugar consumption and re-educating the palate to accept lower sweetness [53, 54], while limiting the potential for consumers to subconsciously overcompensate for perceived 'caloric savings' attained by AS usage [55]. Indeed, the American Heart Association and American Diabetes Association state that the potential benefits of AS will not be appreciated if there is compensatory intake of energy from other macronutrient sources [56]. In an attempt to overcome the impact of psychological cues on EI and body weight, a double-blind study design was used in REFORM. However, in contrast to a previous study [57], the majority of participants correctly identified the regular and reformulated foods, due to the significant lower reported taste and palatability of the reformulated products. Moreover, our consumer acceptance findings indicate that significant improvements to the sensory qualities of a selection of sugar-reduced products, that were included in the REFORM intervention, are necessary [58]. This may have influenced conscious energy compensation and highlights the challenge faced by food industry in matching these sensory attributes in artificially sweetened foods and beverages.

In conclusion, consumption of sugar-reformulated foods and beverages as part of a blinded dietary exchange, resulted in a significant reduction in sugar intake, but had no significant effect on body weight, BP, fasting serum glucose or lipid concentrations, which was in part due to energy balance compensation. Future work is required to 
determine whether these findings have relevance to energy compensation dynamics in obese populations or fat accumulation in healthy populations over a long-term dietary intervention period.

Acknowledgments We thank the study participants for their time and enthusiasm; Dr Kim Jackson, Rada Mihaylova and Jan Luff for their support throughout the study; Prof Sue Todd for her statistical advice; Aoife Curran, Brian Heffernan, Dr Charlotte Mills, Patricia Shaw and Annabel Su for their assistance with data collection, the blinding of intervention foods or data entry. The authors' responsibilities were as follows: O.M. and J.A.L. designed the study; O.M. and J.L.J. conducted the study; O.M. performed the analysis; O.M. and J.A.L. prepared the manuscript; and J.A.L. had primary responsibility for the final content. All authors read and approved the final manuscript.

\section{Compliance with ethical standards}

Conflict of interest This work was supported by Sugar Nutrition UK; however, the sponsor had no input into the study hypothesis and design, data analysis and interpretation. J.A. Lovegrove is an expert on the UK Scientific Advisory Committee for Nutrition (SACN). All other authors declare no conflicts of interest.

Open Access This article is distributed under the terms of the Creative Commons Attribution 4.0 International License (http://creativecommons.org/licenses/by/4.0/), which permits unrestricted use, distribution, and reproduction in any medium, provided you give appropriate credit to the original author(s) and the source, provide a link to the Creative Commons license, and indicate if changes were made.

\section{References}

1. Hu FB (2013) Resolved: there is sufficient scientific evidence that decreasing sugar-sweetened beverage consumption will reduce the prevalence of obesity and obesity-related diseases. Obes Rev 14:606-619. doi:10.1111/obr.12040

2. Malik VS, Pan A, Willett WC, Hu FB (2013) Sugar-sweetened beverages and weight gain in children and adults: a systematic review and meta-analysis. Am J Clin Nutr. doi:10.3945/ ajcn.113.058362

3. Te Morenga LA, Howatson AJ, Jones RM, Mann J (2014) Dietary sugars and cardiometabolic risk: systematic review and meta-analyses of randomized controlled trials of the effects on blood pressure and lipids. Am J Clin Nutr 100:65-79. doi:10.3945/ajen.113.081521

4. Te Morenga L, Mann J, Mallard S (2013) Authors' reply to Cottrell and Wittekind. BMJ (Clin Res ed.) 346:f1240. doi:10.1136/ bmj.f1240

5. van Buul VJ, Tappy L, Brouns FJ (2014) Misconceptions about fructose-containing sugars and their role in the obesity epidemic. Nutr Res Rev 27:119-130. doi:10.1017/s0954422414000067

6. World Health Organization Guideline: Sugars intake for adults and children (2015). http://who.int/nutrition/publications/guidelines/sugars_intake/en/ (cited 20 April 2015)

7. Scientific Advisory Committee on Nutrition Update on Trans Fatty Acids and Health. Position statement (2007). http://www. sacn.gov.uk/pdfs/sacn_trans_fatty_acids_report.pdf (cited 2 March 2014)
8. Department of Health (1991) Dietary Reference Values for Food Energy and Nutrients for the United Kingdom. vol. 41: Report on Health and Social Subjects. London: HMSO

9. Department of health national diet and nutrition survey: results from years 1 to 4 (combined) of the rolling programme for 2008 and 2009 to 2011 and 2012. 2014. https://www.gov.uk/government/publications/national-diet-and-nutrition-survey-resultsfrom-years-1-to-4-combined-of-the-rolling-programme-for2008-and-2009-to-2011-and-2012 (cited 14 May 2014)

10. Scientific Advisory Committee on Nutrition Carbohydrates and Health. (2015). https://www.gov.uk/government/uploads/system/ uploads/attachment_data/file/445503/SACN_Carbohydrates_ and_Health.pdf (cited 11 August 2015)

11. Kelly SA, Summerbell C, Rugg-Gunn AJ, Adamson A, Fletcher E, Moynihan PJ (2005) Comparison of methods to estimate nonmilk extrinsic sugars and their application to sugars in the diet of young adolescents. Br J Nutr 94:114-124

12. van Raaij J, Hendriksen M, Verhagen H (2009) Potential for improvement of population diet through reformulation of commonly eaten foods. Public Health Nutr 12:325-330

13. Horner KM, Byrne NM, Cleghorn GJ, Naslund E, King NA (2011) The effects of weight loss strategies on gastric emptying and appetite control. Obes Rev 12:935-951. doi:10.1111/j.1467-789X.2011.00901.x

14. Stubbs RJ, Hughes DA, Johnstone AM, Whybrow S, Horgan GW, King N, Blundell J (2004) Rate and extent of compensatory changes in energy intake and expenditure in response to altered exercise and diet composition in humans. Am J Physiol Regul Integr Comp Physiol 286:R350-R358. doi:10.1152/ ajpregu.00196.2003

15. Sørensen LB, Vasilaras TH, Astrup A, Raben A (2014) Sucrose compared with artificial sweeteners: a clinical intervention study of effects on energy intake, appetite, and energy expenditure after 10 week of supplementation in overweight subjects. Am J Clin Nutr 100(1):36-45. doi:10.3945/ajen.113.081554

16. Hall KD, Sacks G, Chandramohan D, Chow CC, Wang YC, Gortmaker SL, Swinburn BA (2011) Quantification of the effect of energy imbalance on bodyweight. Lancet 378:826-837

17. Dhingra R, Sullivan L, Jacques PF, Wang TJ, Fox CS, Meigs JB, D'Agostino RB, Gaziano JM, Vasan RS (2007) Soft drink consumption and risk of developing cardiometabolic risk factors and the metabolic syndrome in middle-aged adults in the community. Circulation 116:480-488. doi:10.1161/ circulationaha.107.689935

18. Stanhope KL, Schwarz JM, Keim NL, Griffen SC, Bremer AA, Graham JL, Hatcher B, Cox CL, Dyachenko A, Zhang W, McGahan JP, Seibert A, Krauss RM, Chiu S, Schaefer EJ, Ai M, Otokozawa S, Nakajima K, Nakano T, Beysen C, Hellerstein MK, Berglund L, Havel PJ (2009) Consuming fructose-sweetened, not glucose-sweetened, beverages increases visceral adiposity and lipids and decreases insulin sensitivity in overweight/ obese humans. J Clin Invest 119:1322-1334. doi:10.1172/ jci37385

19. Black RN, Spence M, McMahon RO, Cuskelly GJ, Ennis CN, McCance DR, Young IS, Bell PM, Hunter SJ (2006) Effect of eucaloric high- and low-sucrose diets with identical macronutrient profile on insulin resistance and vascular risk: a randomized controlled trial. Diabetes 55:3566-3572. doi:10.2337/db06-0220

20. Raben A, Vasilaras TH, Moller AC, Astrup A (2002) Sucrose compared with artificial sweeteners: different effects on ad libitum food intake and body weight after 10 week of supplementation in overweight subjects. Am J Clin Nutr 76:721-729

21. World Health Organization (2003) Diet, nutrition and the prevention of chronic diseases: report of a joint WHO/FAO expert consultation. 916 
22. British Cardiac Society, British Hypertension Society, Diabetes UK, Heart UK, Primary Care Cardiovascular Society, The Stroke Association (2015) JBS 2: Joint British Societies' guidelines on prevention of cardiovascular disease in clinical practice. Heart 91(suppl 5):v1-52. doi:10.1136/hrt.2005.079988

23. Stunkard AJ, Messick S (1985) The three-factor eating questionnaire to measure dietary restraint, disinhibition and hunger. J Psychosom Res 29:71-83

24. Martins C, Robertson MD, Morgan LM (2008) Effects of exercise and restrained eating behaviour on appetite control. Proc Nutr Soc 67:28-41. doi:10.1017/s0029665108005995

25. Altman DG, Bland JM (2005) Treatment allocation by minimisation. BMJ 330:843

26. Lockyer $\mathrm{S}$, Tzanetou $\mathrm{M}$, Carvalho-Wells $\mathrm{AL}$, Jackson $\mathrm{KG}$, Minihane AM, Lovegrove JA (2012) SATgene dietary model to implement diets of differing fat composition in prospectively genotyped groups (apoE) using commercially available foods. $\mathrm{Br}$ J Nutr 108:1705-1713

27. Henderson L, Gregory J, Irving K, Swan G (2003) The National Diet and Nutrition Survey: adults aged 19-64 years. vol 2: energy, protein, carbohydrate, fat and alcohol intake. TSO (London)

28. Flint A, Raben A, Blundell JE, Astrup A (2000) Reproducibility, power and validity of visual analogue scales in assessment of appetite sensations in single test meal studies. Int J Obes Relat Metab Disord 24:38-48

29. Englyst HN, Cummings JH (1988) Improved method for measurement of dietary fiber as non-starch polysaccharides in plant foods. J Assoc Off Anal Chem 71:808-814

30. Celis-Morales CA, Perez-Bravo F, Ibanez L, Salas C, Bailey ME, Gill JM (2012) Objective versus self-reported physical activity and sedentary time: effects of measurement method on relationships with risk biomarkers. PLoS ONE 7:9

31. Troiano RP, Berrigan D, Dodd KW, Masse LC, Tilert T, McDowell M (2008) Physical activity in the United States measured by accelerometer. Med Sci Sports Exerc 40:181-188

32. Tudor-Locke C, Bassett DR Jr (2004) How many steps/day are enough? Preliminary pedometer indices for public health. Sports Med 34:1-8

33. Reid M, Hammersley R, Duffy M, Ballantyne C (2014) Effects on obese women of the sugar sucrose added to the diet over 28 d: a quasi-randomised, single-blind, controlled trial. Br J Nutr 111:563-570

34. Henry CJ (2005) Basal metabolic rate studies in humans: measurement and development of new equations. Public Health Nutr 8:1133-1152

35. Millasseau SC, Guigui FG, Kelly RP, Prasad K, Cockcroft JR, Ritter JM, Chowienczyk PJ (2000) Noninvasive assessment of the digital volume pulse. Comparison with the peripheral pressure pulse. Hypertension 36:952-956

36. Wilkinson IB, Fuchs SA, Jansen IM, Spratt JC, Murray GD, Cockcroft JR, Webb DJ (1998) Reproducibility of pulse wave velocity and augmentation index measured by pulse wave analysis. J Hypertens 16:2079-2084

37. O'Rourke MF, Pauca A, Jiang XJ (2001) Pulse wave analysis. Br J Clin Pharmacol 51:507-522

38. Friedewald WT, Levy RI, Fredrickson DS (1972) Estimation of the concentration of low-density lipoprotein cholesterol in plasma, without use of the preparative ultracentrifuge. Clin Chem 18:499-502

39. Luscombe-Marsh ND, Noakes M, Wittert GA, Keogh JB, Foster P, Clifton PM (2005) Carbohydrate-restricted diets high in either monounsaturated fat or protein are equally effective at promoting fat loss and improving blood lipids. Am J Clin Nutr 81:762-772

40. Bellisle F, Drewnowski A (2007) Intense sweeteners, energy intake and the control of body weight. Eur J Clin Nutr 61:691700. doi:10.1038/sj.ejen.1602649
41. Dhurandhar NV, Schoeller D, Brown AW, Heymsfield SB, Thomas D, Sorensen TIA, Speakman JR, Jeansonne M, Allison DB (2014) Energy balance measurement: when something is not better than nothing. Int J Obes. doi:10.1038/ijo.2014.199

42. Dannecker KL, Sazonova NA, Melanson EL, Sazonov ES, Browning RC (2013) A comparison of energy expenditure estimation of several physical activity monitors. Med Sci Sports Exerc 45:2105-2112

43. Reid M, Hammersley R, Hill AJ, Skidmore P (2007) Long-term dietary compensation for added sugar: effects of supplementary sucrose drinks over a 4-week period. Br J Nutr 97:193-203

44. Reid M, Hammersley R, Duffy M (2010) Effects of sucrose drinks on macronutrient intake, body weight, and mood state in overweight women over 4 weeks. Appetite 55:130-136

45. Maersk M, Belza A, Stodkilde-Jorgensen H, Ringgaard S, Chabanova E, Thomsen H, Pedersen SB, Astrup A, Richelsen B (2012) Sucrose-sweetened beverages increase fat storage in the liver, muscle, and visceral fat depot: a 6-mo randomized intervention study. Am J Clin Nutr 95:283-289

46. Raben A, Moller BK, Flint A, Vasilaris TH, Christina Moller A, Juul Holst J, Astrup A (2011) Increased postprandial glycaemia, insulinemia, and lipidemia after 10 weeks' sucrose-rich diet compared to an artificially sweetened diet: a randomised controlled trial. Food Nutr Res 55:20

47. Malik VS, Popkin BM, Bray GA, Després J-P, Hu FB (2010) Sugar-sweetened beverages, obesity, type 2 diabetes mellitus, and cardiovascular disease risk. Circulation 121:1356-1364. doi:10.1161/circulationaha.109.876185

48. Yang Q, Zhang Z, Gregg EW, Flanders WD, Merritt R, Hu FB (2014) Added sugar intake and cardiovascular diseases mortality among us adults. JAMA Intern Med 174:516-524

49. Cox CL, Stanhope KL, Schwarz JM, Graham JL, Hatcher B, Griffen SC, Bremer AA, Berglund L, McGahan JP, Havel PJ, Keim NL (2012) Consumption of fructose-sweetened beverages for 10 weeks reduces net fat oxidation and energy expenditure in overweight/obese men and women. Eur J Clin Nutr 66:201-208

50. Qi Q, Chu AY, Kang JH, Jensen MK, Curhan GC, Pasquale LR, Ridker PM, Hunter DJ, Willett WC, Rimm EB, Chasman DI, Hu FB, Qi L (2012) Sugar-sweetened beverages and genetic risk of obesity. N Engl J Med 367:1387-1396. doi:10.1056/NEJMoa1203039

51. Sanders TA, Lewis FJ, Goff LM, Chowienczyk PJ (2013) SFAs do not impair endothelial function and arterial stiffness. Am J Clin Nutr 98:677-683. doi:10.3945/ajen.113.063644

52. He FJ, Brinsden HC, Macgregor GA (2014) Salt reduction in the United Kingdom: a successful experiment in public health. J Hum Hypertens 28:345-352

53. Stuckey B (2013) Taste: surprising stories and science about why food tastes good. Atria Books, London

54. Yang Q (2010) Gain weight by "going diet?" Artificial sweeteners and the neurobiology of sugar cravings: neuroscience 2010. Yale J Biol Med 83:101

55. Mattes RD, Popkin BM (2009) Nonnutritive sweetener consumption in humans: effects on appetite and food intake and their putative mechanisms. Am J Clin Nutr 89:1-14

56. Gardner C, Wylie-Rosett J, Gidding SS, Steffen LM, Johnson RK, Reader D, Lichtenstein AH (2012) Nonnutritive sweeteners: current use and health perspectives: a scientific statement from the American Heart Association and the American Diabetes Association. Diabetes Care 35:1798-1808

57. de Ruyter JC, Olthof MR, Seidell JC, Katan MB (2012) A trial of sugar-free or sugar-sweetened beverages and body weight in children. N Engl J Med 367:1397-1406

58. Markey O, Lovegrove JA, Methven L (2015) Sensory profiles and consumer acceptability of a range of sugar-reduced products on the UK market. Food Res Int 72:133-139. doi:10.1016/j. foodres.2015.03.012 